\title{
Stereo and scanning electron microscopy characteristics of poultry breeding beetle (alphitobius diaperinus) - a filamentous toxigenic fungi carrier
}

\author{
Carlos Eduardo da Silva Soares ${ }^{1 *}$, André Weber ${ }^{2}$, Vildes Maria Scussel ${ }^{1}$ \\ ${ }^{1}$ Laboratory of Mycotoxicology and Food Contaminants, Department of Food Science and Technology, Federal University of Santa Catarina, \\ Brazil; ${ }^{2}$ Federal Institute Catarinense - Campus Araquari, SC, Brazil
}

\section{A B S TR A C T}

This study isolated Alphitobius diaperinus (live and dead) insects from shed's aviary bed to investigate their fungi spores distribution (that affects chicken health and meat production) and their accumulation sites (dorsal \& ventral) characteristics by different microscopies (stereo and scanning electron). Despite live beetles being the main fungi spore carriers, the dead ones had far more spores attached on their body exoskeleton thereby being a focus of infection. That was due to the anatomical sites favoring spores trapping effect, together with beetles' different moisture content. Regarding the spores distribution and so the hyphae presence \& mycelia concentration on dead A.w diaperinus, they were mainly detected at the (a) elytra, elytral suture and pronotum (on the dorsal side). Despite that, the highest spores/mycelia concentration was at the mouthparts, prosternum and legs (femur \& tarsus) (on the ventral side). Indeed the beetle's ventral anatomical microscopic structures (mouthparts \& legs) sheltered the highest fungi spores concentration and colonies proliferation. Thus dead beetle colonies growth lead to spore multiplication, their dissemination throughout the aviary bed environment and so their contact to chicken feet and body, leading to discomfort and diseases development/mycotoxicosis. The filamentous fungi were most detected from the Aspergillus and Penicillium genera. Therefore dead beetles should be removed from aviary (at each 45 breeding cycle) to reduce contamination. They represent rich substrates for fungi development with possibility of toxin formation, apart from the chicken diseases exposure due to their insects eating habits.

Key-words: aviary bed, fungi, mycotoxins, poultry, vectors

\section{INTRODUCTION}

Insects of different genera and species infest poultry farming during breeding and can distribute fungi spores (deteriorating and toxigenic) throughout shed's facilities including the aviary bed (Lacey et al., 1996; Chandler et al., 1997; Green, 2008; Soares et al., 2017). They can mechanically transport fungi spores on their bodies, thus increasing significantly the chicken infections rate (Kluth, 2002; Quirino, 2008). Aviary sheds' temperature and humidity conditions play an important role in in insects infestation in poultry breeding there by resulting in fungi infections including other living organisms (mites, bacteria and virus), thus affecting chicken health (Scussel, 2002; Hazeleger et al., 2008; Bosly et al., 2014; Soares et al., 2017).
Infestation in aviary beds of insect such as of Alphitobius diaperinus (Coleoptera, Tenebrionidae), commonly called darkling beetle, is responsible for large losses in poultry farming (Skov et al., 2004; Rolf and Schiller, 2016; Soares et al., 2017). Apart from fungi also bacteria such as Campylobacter jejuni, Salmonella enteric among others, have been reported to contaminate aviary bed and chicks (Hazeleger et al., 2008). When there is shortage of food during rearing, chicks/chicken begin to eat those insects (living organisms contaminated) leading to diseases development. This also results in decreased chicken feed conversion, diarrhea, stress and reduces body weight (Matias, 1992; Despins and Axtell 1995; Skov et al., 2004). Other Alphitobius species such as A. laevigatus (Fabricius), A. stephens and A. piceus (Oliver) have been isolated from stored grains and flour (Hagstrum, 2017).

\section{${ }^{*}$ Corresponding author:}

Carlos Eduardo da Silva Soares, Laboratory of Mycotoxicology and Food Contaminants, Department of Food Science and Technology, Federal University of Santa Catarina, Brazil. E-mail: c.ess@posgrad.ufsc.br.

Received: 18 July 2017; Accepted: 15 February 2018 
During the day, those insects remain under the aviary bed surface, inside the shed structures (columns/walls) and equipment (feeders). In nocturnal period they become more active, attracted by the light (moving in and out of the aviary) and distributing fungi spores (Paiva, 2000). Those spores can be carried by adhesion on insect exoskeleton waxy surface and so under its cuticles (Noh et al., 2016; Dittmer et al., 2011, Bruns, 1995; Lenardon et al., 2010). Insect constant movement, within an ecosystem, contributes to Aspergillus, Penicillium, Mucor and Rhizopus (all storage fungi), including Fusarium (field fungi) spores dispersal (Bidochka 1997; Saint Geroges-Gridelet, 1984; Scussel et al, 2011; (Slipinski \& Escalona, 2016).

Regarding the effect of fungi presence in chicken breeding environment, they can lead to development of diseases in chicken/chicks (aspergillosis) and embryos (susceptibility to fungal effects during posture contamination) including spores inhalation (lung mycosis). Despite that, some of those fungi genera can produce mycotoxins. Mainly the filamentous fungi species (A. flavus \& A. parasiticus, P. ochraceus, F. verticilioides, F. grasminearum - aflatoxins, ocratoxin A, fumonisins, deoxinivalenol and zearalenon, respectivelly) and can contaminate aviary beds (high humidity/feed residues) and so the chicken (Placinta, 1999; Van Broeckeoven et al., 2017). In young birds, mycotoxin intoxication lead to high mortality (Wang, 2012; Arné et al., 2011; Andreatti Filho, 2000). It should be noted that storage fungi are found spread on the poultry farming machinery (equipments mills and hoppers) and in the storage environment (sheds, warehouses, silos) as long as good conditions (temperature and humidity) are present (Mallmann, 1994; Saleemi et al., 2010).

Considering the extensive poultry farming's activities; the problems with insect infestation; the consecutive and high number (x8) of chicken breeding/rearing cycles ( 45 days each) produced per year (same aviary bed) and the development of fungi infections that reduces chicken/meat sanitary conditions an investigation was carried out on the $A$. diaperinus (adult \& larvae stages) microorganisms carrier characteristics and its main anatomical sites able to shelter and spread fungi spores (aviary bed \& chicken environment contamination) by stereo (SM) and scanning electron (SEM) microscopies.

This is the first work investigating $A$. diaperinus detailed anatomic characteristics and fungi accumulation sites reported by SM \& SEM.

\section{MATERIAL AND METHODS}

\subsection{Material}

(a) Samples: Insects (A. diaperinus), extracted from aviary bed (at the $45^{\text {th }}$ day of chicken breeding, no insecticide application), both live and dead (adults and larvae stages). (b) Equipment: tweezers, Prolab (Sao Paulo, SP, Brazil); sieve system, 9-16 mesh $(2.00-1.00 \mathrm{~mm} / \mu \mathrm{m}$ apert., 10-18 USM/ASTM) Beffer (Caieiras,SP, Brazil); a meter, model Aqua- Lab4TE, Decagon (Sao Jose dos Campos, SP, Brazil);drying oven, Olidef-cz (Ribeirao Preto, SP, Brazil); stereo microscope, model Opzt (x180), coupled to a color imagecapture camera, model OPT14 MP, Opticam (Doral, Fl., USA); scanning electron microscope (x5000), model JSM- 6390LV, Jeol (Peabody, Mass., USA) and gold coating machine, model EM-Scd500, Leica (Leider, Ill., USA). Other materials: stubs (small metal blocks, 9 diameter and $10 \mathrm{~mm}$ height).

\subsection{Method}

(a) Aviary bed and insect collection: Prior to the procedure of insect isolation, an infested aviary bed sample (mc: $40.6 \%$, $\left.\mathrm{a}_{\mathrm{w}}: 0.98\right)$ was collected as follows (a.1) aviary bed- a portion (100 g) was obtained from the shed's floor $(10 \mathrm{~cm}$ depth) after 45 days of chicken complete growth stage, as reported by Soares et al. (2017) and proceeded to (a.2) insects isolation - separated beetle samples (both growth stages: adult \& larvae) were collected (live* and dead) from the aviary bed as in (a.1), through sieving (9-16 mesh) by picking them with tweezers for the microscopy analysis preparation. *killed by applying a insecticide (cypermethrin) solution in acetonitrile.

(b) Insects preparation for microscopy: Insects (both growth stages) were prepared for SM and SEM, as follows (b.1) $S M$ - the whole (isolated alive \& dead) and different insects parts (dorsal e ventral) were separated in Petri dishes (and so the larvae and directly taken for SM observation; for (b.2) SEM - those samples from (b.1) were prepared by stubs mounting and their surfaces gold coated, as reported by Scussel et al. (2014a). Briefly, insects were fixed on stubs (containing carbon double-sided tape), then vacuum gold coated (by placing them onto a Planetary Gold Coater stubs holder, vacuum applied and coated with a $40 \mathrm{~nm}$ gold layer).

(c) Microscopy observation: Insects whole and parts samples prepared in (b) were taken for microscopy observation, (c.1) $S M$ - they were directly taken (from b.1) for characteristics identification of head, thorax, abdomen, legs at different amplification (26 to $x 80)$ and so the special anatomical parts that shelter fungi spores and/or growing colonies; for (c.2) $S E M$ - the stubs with the insects parts were taken to the SEM microscope to investigate the fungi presence/distribution/ proliferation/genera identification (mycelia, hyphae, conidia) on insects' parts. Also the sites where they are mainly adhered onto the insect body $(25$ to x1,100) were investigated.

\section{RESULTS AND DISCUSSION}

Data on the $A$. diaperinus microscopic characteristics (SM \& SEM) regarding the anatomical parts that shelter fungi spores at high concentration, were identified (Martins 
et al., 2016). The fungi spores distribution/accumulation, whether on beetles captured alive or found dead in the aviary bed, were registered, including their differences. Fig 1-6 present beetles (adult $\&$ larvae stages) characteristics and the main parts that most accumulate fungi spores (either on dorsal or ventral; and whether alive or dead).

\subsection{Alphitobius diaperinus microscopic characteristics}

In order to understand the $A$. diaperinus insect's fungi spores transport through the poultry breeding chicken environment and their effect on chicken safety, it was necessary initially to identify its micro-morphological characteristics (adult \& larvae stages) (Povaluk, 2017 and Faruk et al., 2005). The main SM \& SEM beetle (both stages) different body parts (head/thorax/abdomen) characteristics are shown in Fig 1 and 2, respectively.

SM: regarding the beetle exoskeleton morphological parts at (a) adult stage, it was possible to identify some details by SM (up to $\mathrm{x} 80$ ) of the three different parts that comprise the whole insect, as follows. At head - the eyes, antennae \& mouthparts (that comprises of different robust small structures - to be seen on SEM); thorax - pronotum (dorsal) \& prosternum showing its hairiness distributed along its hypomeron with thoraxic legs (ventral); abdomen - the two elytrons (with the suture between them) \& hindwings (dorsal) and ventrites \& legs (femur/tibia/tarsus) (ventral). Fig 1.a shows details of adult $A$. diaperinus by SM. On the other hand, the beetle at the (b) larvae stage, which is seen as a hyaline structure by $\mathrm{SM}$, comprises also of three main parts, i.e., head - a pair of immature eyes, antennae \& mouthparts; thorax - with the $\mathrm{pro} / \mathrm{meso} / \mathrm{metathorax}$ and abdomen - segments, legs \& spines. Fig 1.b shows the dorsal view larvae structures.

SEM: the more detailed main beetles adult and its larvae stage micro-morphological SEM (up to x1,100) characteristics were as follows. For the (a) adult stage: the head - presents one pair of compound eyes (i.e., many lenses/ ommatidia pack into hexagonal array with dome format facets), mouthparts (set of robust maxillae, maxillary palp, labrum, labial palp, labium, mandible and hairiness) \& the antennae (funicle and club, with pores and spines). At the thorax region - is the hypomeron (a broad pubescent area) $\&$ the prosternum (a strongly developed front at the medial part) that has a thick hairiness (sensitive structures near the hypomeron anterior edge) on ventral side. On the other side, is the pronotum (also hard structure, that some species use it in combat) at the (dorsab). The abdomen-comprises of a pair of elytra \& its suture (containing intercostal cuticle layer) (dorsal) and ventrites with legs - femur, tibia (both with row of spines with different sizes \& shapes, tibial spurs) \& tarsus (comprises of a series of tarsomeres - tarsal segments, with a pair of claws at the end, each) (ventral). Figs 2a.1-a.4 show some adult $A$. diaperinus structures. Other beetle`s adult characteristics that also trap fungi are shown in the next Section (3.2). Regarding the SEM characteristics of the beetle at (b) larvae stage: it was possible to observe the head with a comprehensive set of structures as follows, a pair of larval eyes (rather visible), mouthparts (similar to the adult beetle) and antennae (antennal segments I-III and a thin apical segment); the thorax - with the prothorax containing a pair of legs and abdomen - with its several segments called tergites (dorsal) and sternites (ventral) with spines. Figs 2b.1 and b. 2 show the features on larvae dorsal side.

\subsection{Alphitobius. diaperinus fungi spores accumulation and colonies proliferation - anatomical sites}

Utilizing both microscopy techniques, specially SEM, it was possible to clearly identify the beetle's anatomical fungi sheltering special sites. Those that (a) most concentrate spores (adhered easily on insect body) and/or fungi colonies (mycelia/hyphae/reproductive structures) growth. Also those sites that (b) provide condition to allow fungi infection to take place (high humidity \& rich substrate) (Butt et al., 1995). All of them, thus contribute to the spores/fungal transfer throughout the poultry environment and animals are shown in Figs 3 to 6.

SM: by searching fungi presence/accumulation on the (a) adult stage, when the beetle was captured (a.1) alive by SM, it was possible to slightly visualize spores adhered on them
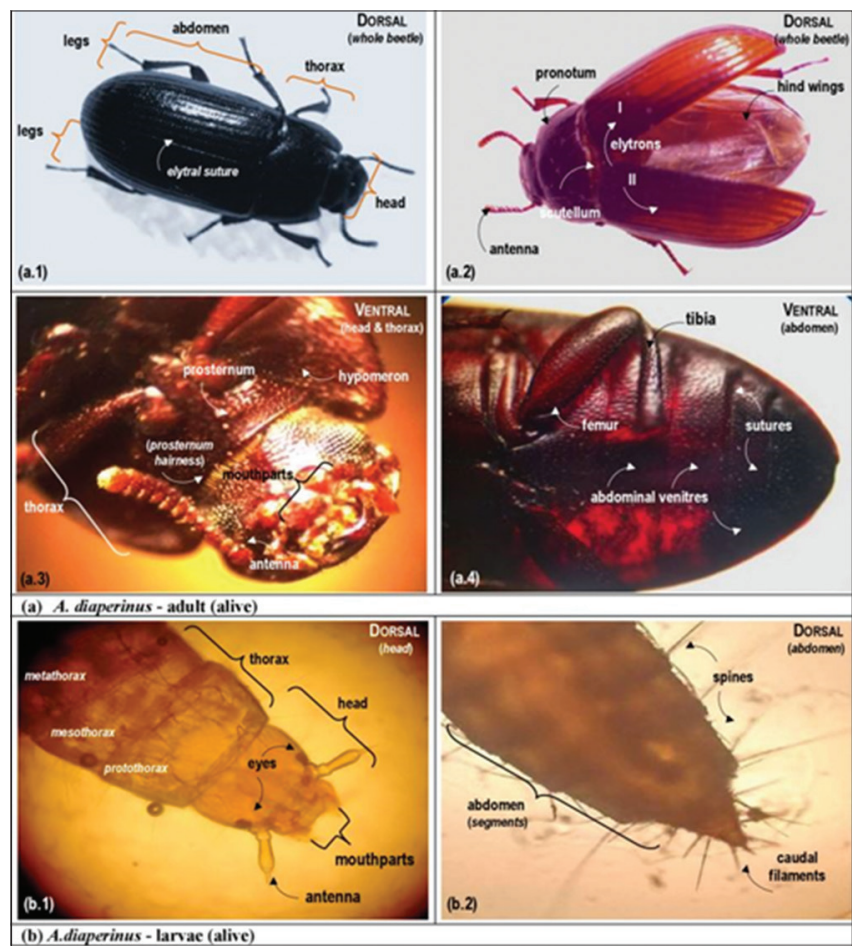

Fig 1. Stereo micrographs of alive Alphitobius diaperinus (Panzer) characteristics isolated from aviary bed: (a) adult stage (dorsal - a.1/a.2; ventral - a.3/a.4) and its (b) larvae stage (dorsal - b.1/b.2 for head and abdomem, respectively) [26 to $\mathrm{x} 100$ ] 
(although they were, apparently, not visible by naked eye - not seemed to be infected). On the other hand, from all the (a.2) dead beetles and their parts that were viewed (head/thorax/ abdomen) both, on the dorsal \& ventral sides, it was registered high fungi infections with colonies growth throughout the insect's body (Bleiker et al., 2009). Despite that, they were more concentrated in certain parts as follows (in decreasing order of spores - colonies concentration - infections): on the thorax (prosternum/pronotum), followed by the legs (tibia/ tarsus), head (mouthparts) and abdomen (elytra). (Fig 3). Fungi reproductive structures were clearly more visible, including hyphae, adhered on to the dorsal (both at elytra suture and pronotum) side (Fig 3 a.1, a.2). On the ventral side, the fungi colonies were mostly concentrated on the thorax (prosternum); legs (tibia/tarsus) and head (mouthparts) (Fi3.a.3 and a.4) (Butt et al, 1992). At the (b) larvae stage, the presence of spores was seen throughout larvae morphological structures, however more concentrated on its abdomen (segments) (Fig 3.b). Those features and spores location observed by SM, will be seen more visible and detailed by SEM micrographs next.

SEM: when beetles were investigated for their anatomical sites fungi accumulation at higher magnification, their distribution were specified more accurately. At the (a) adult

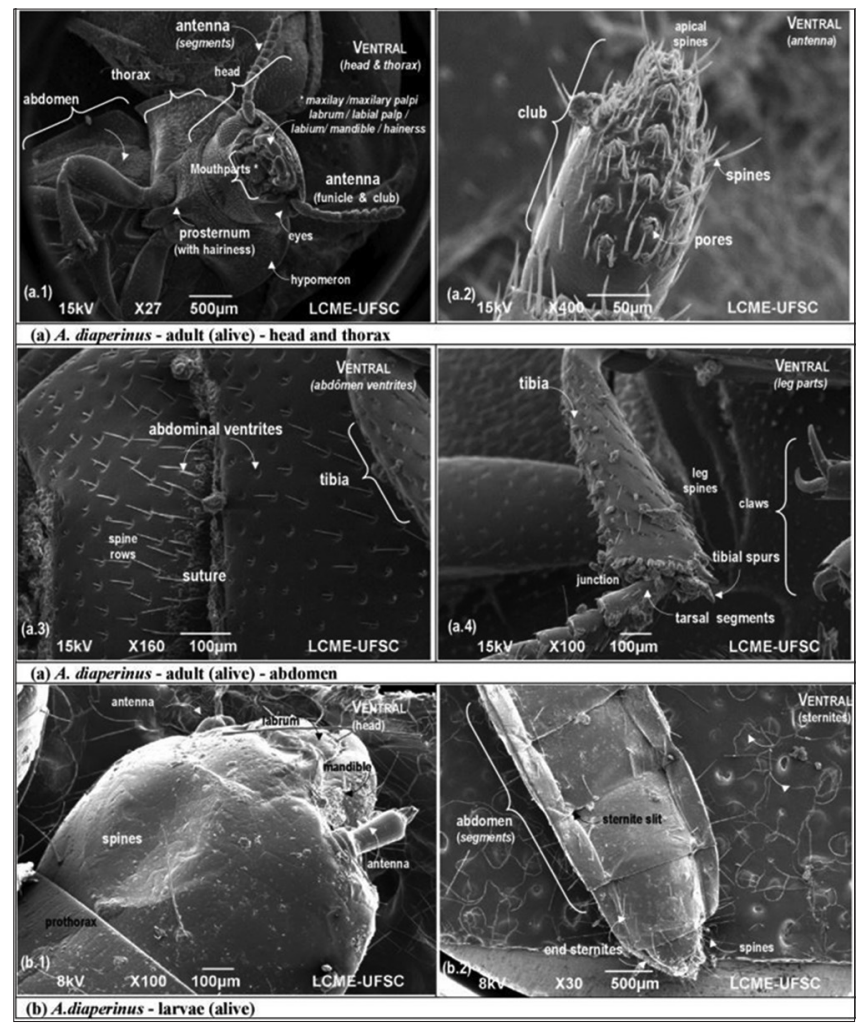

Fig 2. Scanning electron micrographs of Alphitobius diaperinus (Panzer) anatomical special parts characteristics isolated from aviary bed: (a) adult stage - (a.1) head \& prosternum (a.2) antenna (club); (a.3/a.4) abdomen and (b) larvae stage - (b.1/b.2) head and abdomen respectively [27 to $\mathrm{x} 400]$. stage, when beetle was captured (a.1) alive, the spores (conidia) were mainly adhered (concentrated) on the abdominal ventrites. On the other hand, in the (a.2) dead beetles, high fungal infections were observed in both, at the dorsal and ventral regions (colonies development). The presence of reproductive structures (was mainly on the elytral suture (abdomen), on the dorsal region (Fig 4.a-f). Next, they were seen on the head (mouthparts - mandible and hairiness) and thorax (prosternum hairiness) as high colonies infection with conidia spread all over, followed by the abdomen (ventrites) and legs (tibia/tarsus) (ventral region) (Fig 5a,b). The filamentous fungi most detected were from the Aspergillus and Penicillium genera (Fig 4.c/d and e/f, respectively). It is important to emphasize, that the dead (b) larvae stage: micro-morphological sites of fungi accumulation were observed mainly on the head structures of mouthparts \& antennae of the thorax, prothorax and abdomen segments (tergites and sternites) (Fig 6).

\subsection{A. diaperinus proliferation in poultry rearing facilities versus chicken health and safe meat production}

Considering the spores presence and fungi proliferation detected in the $A$. diaperinus in the current study and its obvious dispersal throughout the poultry breeding shed's, one can conclude that they also disseminate diseases and affect chicken well-being during their growth, thus

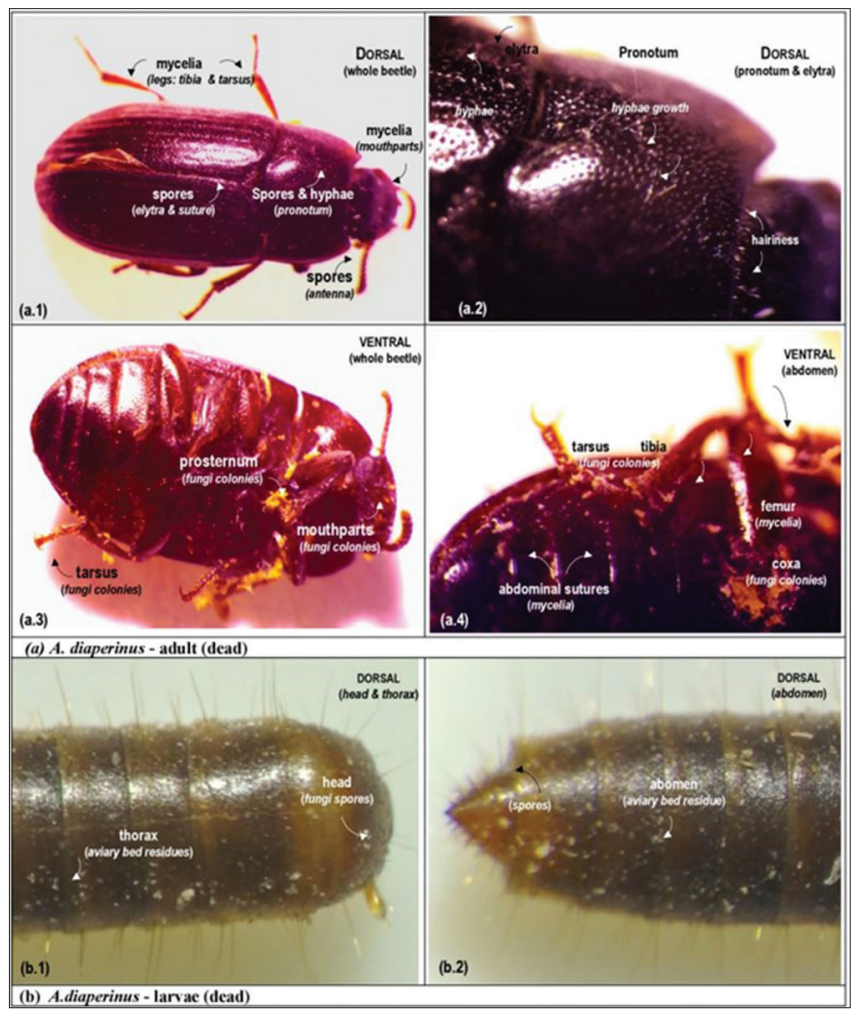

Fig 3. Stereo micrographs of dead Alphitobius diaperinus (Panzer) isolated from aviary bed fungi contaminated/infected distribution: (a) adult stage (dorsal - a.1/a.2; ventral - a.3/a.4) and (b) larvae stage (dorsal view) [26 to x160]. 


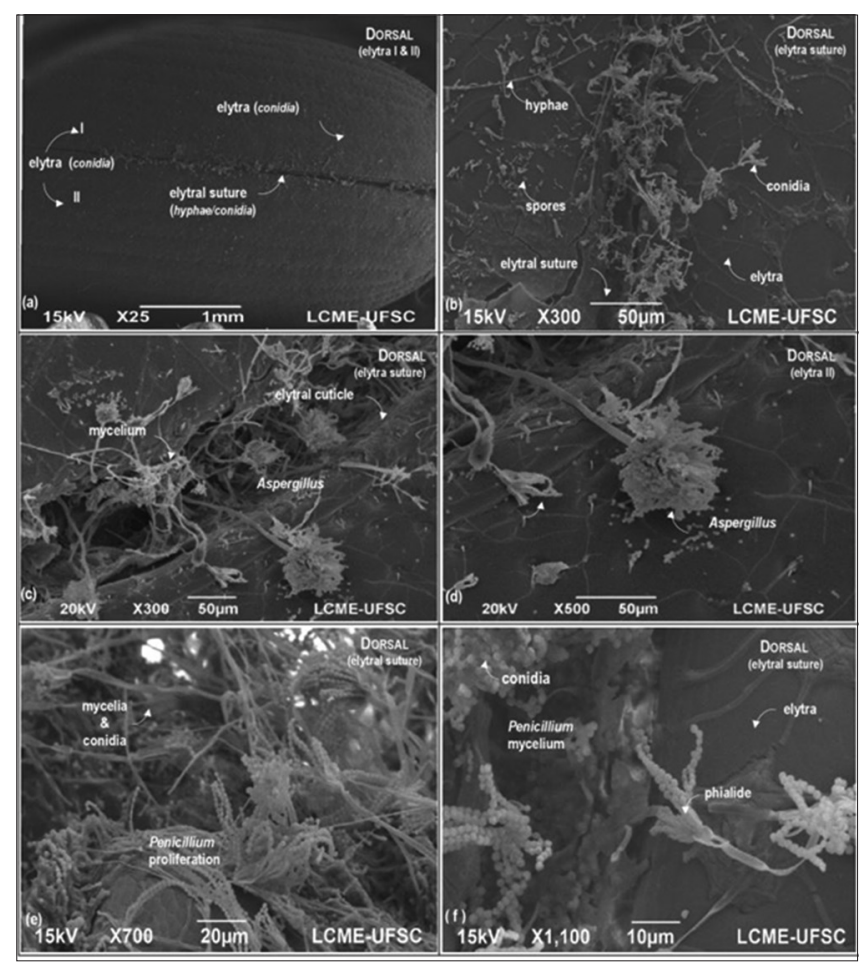

Fig 4. Scanning electron micrographs of $A$. diaperinus (PANZER) DORSAL (ABDOMEN, ELYRAL SUTURE) isolated from aviary bed FUNGI INFECTED/CONTAMINATED: (a) showing colony proliferation on elytra suture (b) reproductive structures of fungi (hyphae, spores and mycelium) distribution and (c-f) Aspergillus and Penicillium genera reproductive structure $[25$ to $\times 1,100]$.

interfering on meat formation and carcass production (standard size).

A. diaperinus beetles have been reported being ingested by chicken and were detected in poultry pro-ventricles and gizzards post-mortem (da Silva et al., 2001; Soares et al., 2017). That lead to certain concern, as that beetle is carrier of living organisms thus increasing fungal survival on their bodies and environment, thus transmission and reproduction (Moser et al., 2010).

Regarding chicken safety, apart from interfering on their well-being (by insects ingestion and/or discomfort by contact), diseases such as aspergillosis in adults, fungi high susceptibility in embryos (contamination during posture), bacterial infections, allergies (mites proliferation) can take place, apart from spores inhalation (lung mycosis) (Lambkin et al., 2007 and Banjo et al., 2005). Therefore, there is a need to apply control/prevention procedures such organic and/or chemical insecticide applications.

\section{CONCLUSION}

The $A$. diaperuns main anatomical sites that most concentrate fungi spores, leading to their distribution in live beetles were

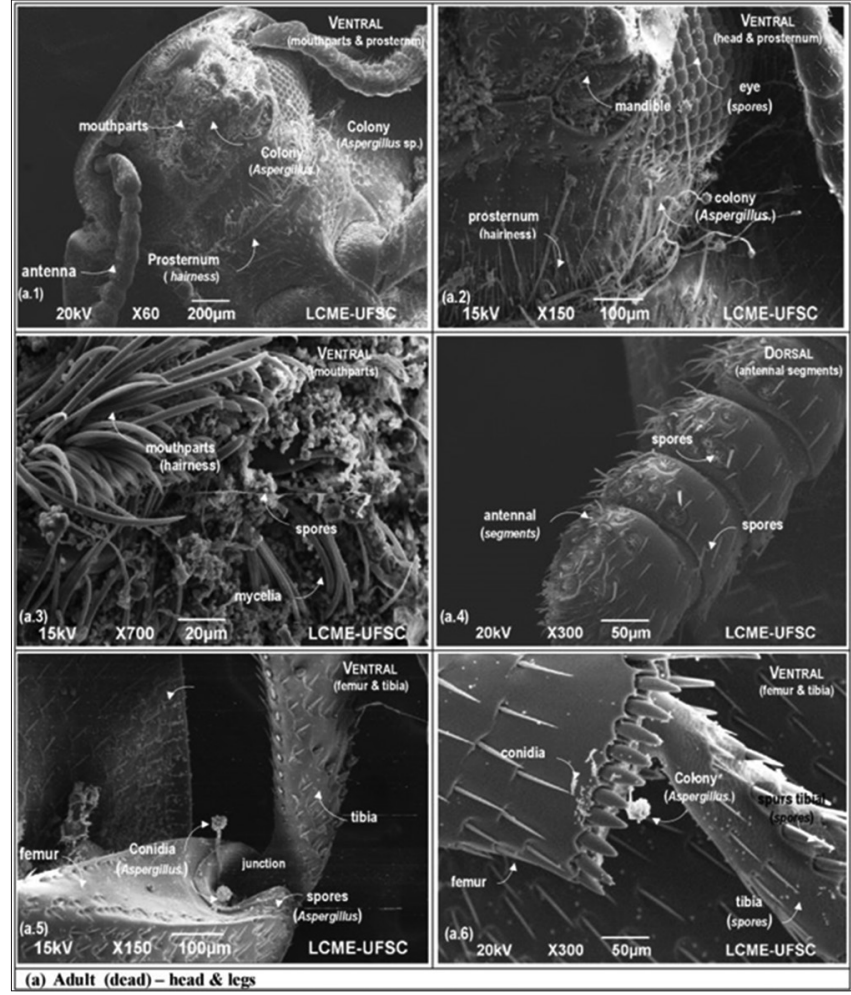

Fig 5. Scanning electron micrographs of Alphitobius diaperinus (Panzer) VENTRAL (HEAD AND LEGS) isolated from aviary bed FUNGI CONTAMINATIO/INFECTED (a.1) showing fungi colonies, (a.2) Aspergillus mycelia, (a.3) highly spores accumulation, (a.4) spores spreading, (a.5/a.6) Aspergillus genera infection [60 to x700].

abdominal ventrites (especially in their sutures) and legs. On the other hand, the main sites on the dead beetles, were the elytral suture, mouthparts, legs and prosternum, which increase contamination spreading by the colonies development.

Regarding the larvae, it had spores adhering throughout the body, being the main contamination on its head.

The fungi most isolated were of Aspergillus and Penicillium genera.

As far as the chicken well-being is concerned, beetles presence in the aviary bed can be ingested causing diseases (bacterial contamination) and fungi infections in chicks and adult animals (that ingestion may be more intense whether the feed supply is short or ceased).

To minimize the problems caused by beetles infestation, chemical (ozone/diatomaceous earth/zinc compounds/ insecticides) and/or biological (plant extracts/insects entomopathogenic species) control should be applied in poultry farms.

This is the first work investigating $A$. diaperinus detailed anatomic characteristics and fungi accumulation sites reported by SM \& SEM. 


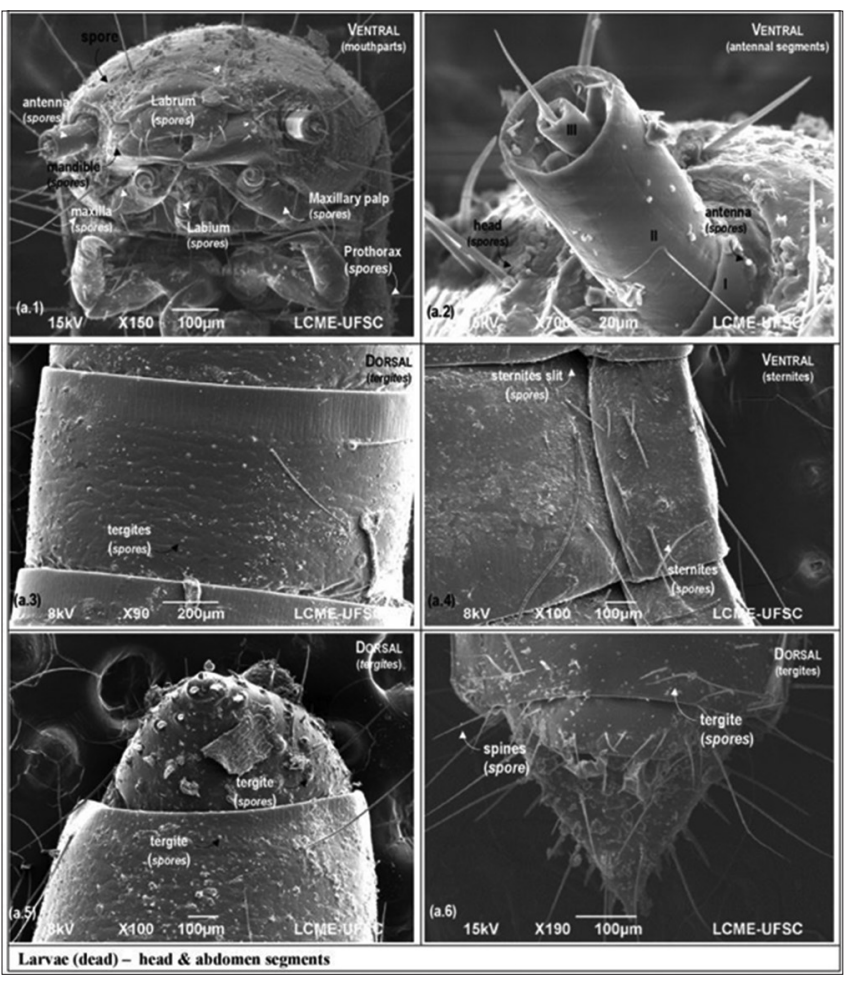

Fig 6. Scanning electron micrograph of Alphitobius diaperinus (Panzer) LARVAE (HEAD \& ABDOMEN) isolated from aviary bed FUNGI INFECTED: (a.1/a.2) head, (a.3-a.6) abdomen [25 to x700].

\section{REFERENCE}

Andreatti, F. R. L. 2000. Enfermidades micóticas. In: A. Jr. Berchieri, M. Macari. (Eds.), Doenças das Aves. Facta, Campinas, pp. 369-378.

Arné, P., S. Thierry, D. Wang, M. Deville, G. Le Loc'h, A. Desoutter, F. Férménia, A. Nieguitsila, W. Huang, R. Chermette and J. Guillot. 2011. Aspergillus fumigatus in poultry. Int. J. Microbiol. 1-14.

Bidochka, M. J., R. J. S. Leger and D. W. Roberts. 1997. Mechanisms of deuteromycete fungal infections in grasshoppers and locusts: An overview. Mem. Entomol. Soc. Can. S171: 213-224.

Bleiker, K. P., S. E. Potter, C. R. Lauzon and D. L. e Six. 2009. Transporte de simbiontes fúngicos por besouros de pinheiros. O Entomol. Can. 5: 503-514.

Bosly, H. A. and M. A. Kawanna. 2014. Fungi species and red flour beetle in stored wheat flour under Jazan region conditions. Toxicol. Ind. Health. 4: 304-310.

Bruns, T. D. 1995. Thoughts on the processes that maintain local species diversity of ectomycorrhizal fungi. Plant Soil. 1: 63-73.

Butt, T. M., M. Barrisever, J. Drummond, T. H. Schuler, F. T. Tillemans and N. Wilding. 1992. Pathogenicity of the entomogenous, hyphomycete fungus, Metarhizium anisopliae against the chrysomelid beetles Psylliodes chrysocephala and Phaedon cochleariae. Biocontrol Sci. Technol. 4: 327-334.

Butt, T. M., L. Ibrahim, S. J. Clark and A. Beckett. 1995. O comportamento de germinação de Metarhizium anisopliae na superfície do pulgão e das cutículas do besouro da pulga. Pesqui. Micol. 8: 945-950.

Chandler, D., D. Hay, A. P. Reid. 1997. Sampling and occurrence of entomopathogenic fungi and nematodes in UK soils. Appl. Soil Ecol. 5: 133-141. da Silva, G. S., V. A. Veronez, G. P. de Oliveira, B. F. de Almeida H. C. da Silva and M. V. Meireles. 2001. Evaluations of sampling methods for "darkling beetles" (Alphitobius diaperinus Panzer) (Coleoptera: Tenebrionidae) in the litter of broiler houses. Semina. 1: 73-76.

Despins, J. L. and R. C. Axtell. 1995. Feeding behavior and growth of broiler chicks fed larvae of the darkling beetle, Alphitobius diaperinus. Poultry Sci. 74: 331-336.

Dittmer, N. T., Y. Hiromasa, J. M. Tomich, N. Lu, R. W. Beeman, K. J. Kramer and M. R. Kanost. 2011. Proteomic and transcriptomic analyses of rigid and membranous cuticles and epidermis from the elytron and hind wings of the red flour beetle, Tribolium castaneum. J. Proteome Res., 11(1): 269-278.

Faruk, S. I., D. R. Das and S. Khatun. 2005. Effects of UV-radiation on the larvae of the lesser mealworm, Alphitobius diaperinus (Panzer) (Coleoptera: Tenebrionidae) and their progeny. J. Biol. Sci. 5(4): 444-448.

Hagstrum, D. 2017. Atlas of Stored-Product Insects and Mites. Elsevier, Minesota.

Hazeleger, W. C., N. M. Bolder, R. R. Beumer and W. F. JacobsReitsma. 2008. Darkling beetles (Alphitobius diaperinus) and their larvae as potential vectors for the transfer of Campylobacter jejuni and Salmonella enterica serovar paratyphi B variant java between successive broiler flocks. Appl. Environ. Microbiol., 22: 6887-6891.

Kluth, S., A. Kruess and T. Tscharntke. 2002. Insetos como vetores de patógenos vegetais: Interações mútuas e antagonistas. O Ecologia. 2: 193-199.

Lacey, L. A., J. J. Fransen and R. Carruthers. 1996. Global distribution of naturally occurring fungi of Bemisia, their biologies and use as biological control agents. In: D. Gerling and R. Mayer (Eds), Taxonomy, Biology, Damage, Control and Management. Intercept, Andover.

Lenardon, M. D., C. A. Munro. and N. A. Gow. 2010. Chitin synthesis and fungal pathogenesis. Curr. Opin. Microbiol. 4: 416-423.

Mallmann, C. A., J. M. Santurio and I. Wentz. 1994 Aflatoxinas-aspectosclínicos e toxicológicosemsuínos. Ciência Rural. 3: 635-643.

Matias, R. S. 1992.Controle de Alphitobius diaperinus em piso e cama de aviários. Pesqui. Agropecu. Bras. 27: 205-207.

Martins, C. C., L. F. A. Alves and A. P. Mamprim. 2016. Effect of plant extracts and a disinfectant on biological parameters and pathogenicity of the fungus Beauveria bassiana (Bals.) Vuill. (Ascomycota: Cordycipitaceae). Braz. J. Biol., 2: 420-427.

Moser, J. C., H. Konrad, S. R. Blomquist and T. Kirisits. 2010. Do mites phoretic on elm bark beetles contribute to the transmission of Dutch elm disease. Naturwissenschaften. 97: 219-227.

Noh, M. Y., S. Muthukrishnan, K. J. Kramer and Y. Arakane. 2016. Cuticle formation and pigmentation in beetles. Curr. Opin. Insect Sci. 17: 1-9

Paiva, D. P. 2000. Cascudinho: Biologia. In: Simpósio Brasileirode Avicultura. Núcleo Oeste de Médicos Veterinários, Chapecó, pp. $133-139$

Placinta, C. M., J. P. E. D'mello and A. M. C. Macdonald. 1999. A review of worldwide contamination of cereal grains and animal feed with Fusarium mycotoxins. Anim. Feed Sci. Technol. 78: 21-37.

Povaluk, M. 2017. Ciclo e controle do Alphitobius diaperinus (Coleoptera, Tenebrionidae) no município de quitandinha, PR. Saúde Meio Ambiente. 61: 107-122.

Rolf, G. B. and F. Schiller. 2016. Coleoptera, Beetles. Morphology and Systematics. de Gruyter, Berlin/Boston.

Geroges-Gridelet, S. 1984. Effects of dietary lipids on the population 
growth of Dermatophagoides pteronyssinus. In: D. A. Griffiths and C. E. Bowman. (Eds.), Acarology VI, Ellis Horwood, Chichester, UK.

Saleemi, M. K., M. Z. Khan, A. Khan and I. Javed. 2010. Mycoflora of poultry feeds and mycotoxins producing potential of Aspergillus species. Pak. J. Bot. 421: 427-434.

Scussel, V. M., B. Menithen and K. M. Tonon. 2011. Effects of infection Fusarium/Giberela infection on the quality and safety of grains, flour and other derivatives. Seminar on Giberéla in Winter Cereals. Cap. 10. Berthier, Passo Fundo, pp. 131-175.

Scussel, V. M., D. Manfio, G. D. Savi and E. H. S. Moecke. 2014a. Stereoscopy and scanning electron microscopy of Brazil nut (Bertholletia excels H.B.K.) shell, brown skin and edible part: Part one - healthy nut. J. Food Sci. 79: H1443-H1453.
Slipinski, A., and H. Escalona. 2016. Australian longhorn beetles (Coleoptera: Cerambycidae). Vol. 2. Subfamily Cerambycinae, CSIRO Publishing, Australian.

Green, P. W. C. 2008. Fungal isolates involved in biodeterioration of book-paper and their effects on substrate selection by Liposcelis bostrychophila (Badonnel) (Psocoptera: Liposcelididae). J. Stored Prod. Res., 3: 258-263.

Van Broeckeoven, S., J. M. Gutierrez, T. C. De Rijk, W. C. M. De Nijs and J. J. A. Van Loon. 2017. Degradation and excretion of the Fusarium toxin deoxynivalenol by an edible insect, the yellow mealworm (Tenebrio molitor L.). World Mycotoxin J. 1-8.

Wang, D. Y. 2012. Genetic Diversity and Antifungal Susceptibility of Aspergillus spp. Isolates from Avian Farms in Guangxi, China. Doctoral Dissertation, Agro Paris Tech. 